\title{
Producción científica de la Revista "Memorias del Instituto de Investigaciones en Ciencias de la Salud" (Mem. Inst. Investig. Cienc. Salud)
}

\author{
Scientific production of the Journal "Memorias del Instituto de \\ Investigaciones en Ciencias de la Salud" (Mem. Inst. Investig. \\ Cienc. Salud)
}

\author{
Iván Barrios $^{1}$ (D), Marcelo O’Higgins ${ }^{1}$ (D), *Julio Torales ${ }^{1}$ (iD \\ ${ }^{1}$ Universidad Nacional de Asunción, Facultad de Ciencias Médicas, Cátedra de Psiquiatría. San \\ Lorenzo, Paraguay
}

Cómo referenciar este artículo/ How to reference this article:
Barrios I, O’Higgins M, Torales J. Producción científica de la Revista "Memorias del Instituto de Investigaciones en Ciencias de la Salud" (Mem. Inst. Investig. Cienc. Salud). Mem. Inst. Investig. Cienc. Salud. 2021; 19(1): 6-8

Señora Editora:

La Revista Memorias del Instituto de Investigaciones en Ciencias de la Salud (Mem. Inst. Investig. Cienc. Salud) es una revista científica de acceso gratuito y arbitrado. Es el órgano oficial de publicación del Instituto de Investigaciones en Ciencias de la Salud (IICS) de la Universidad Nacional de Asunción. En la misma se publican contribuciones originales del área de la salud, estando la revista disponible para investigadores del Paraguay y del mundo. La revista se encuentra indexada en diversas bases de datos, entre las que destacan LILACS y SciELO Paraguay.

Las revistas científicas necesitan someterse a procesos de evaluación permanente, con el fin de garantizar que poseen un valor real en la divulgación de los aportes científicos de los investigadores $y$, a su vez, para que más autores tomen conciencia de ese valor y decidan enviar sus trabajos a las revistas más prestigiosas ${ }^{(1,2)}$.

Los procesos de evaluación antedichos pueden realizarse a través de estudios bibliométricos, que permiten analizar las investigaciones de forma cualitativa $y$ cuantitativa, al tiempo que miden la productividad y visibilidad de las revistas en las que estas son publicadas ${ }^{(3)}$. Estos estudios se constituyen en medidas válidas para valorar la producción científica de las revistas académicas y científicas y son herramientas útiles para el desarrollo editorial de las mismas ${ }^{(3,4)}$.

Con base en lo anterior, quiénes escribimos esta misiva tuvimos por objetivo medir la productividad científica de la revista Mem. Inst. Investig. Cienc. Salud, a través de indicadores cienciométricos ofrecidos por el software Publish or Perish ${ }^{(5)}$. Este software es gratuito y recupera las citas de fuentes de datos diversos (incluidos, por ejemplo, los suministrados por Google Scholar), computando así los indicadores más habituales como son el índice-h, el número total de trabajos publicados, entre otros ${ }^{(6)}$.

La estrategia de búsqueda de índices se realizó utilizando el ISSN de la revista Mem. Inst. Investig. Cienc. Salud. Los indicadores proporcionados por Publish or Perish incluyeron: número de artículos, citas totales, citas anuales, citas por artículo, índice $\mathrm{H}$ y autor de cada artículo ${ }^{(6)}$. Se investigó el período incluido entre los años 2015 y 2020.

Se encontraron 739 artículos y un total de 985 citas. El promedio de citas por año es de 197 y el promedio de citas por artículo, de 1,33. El índice $\mathrm{H}$ de la revista es de 13, lo que significa que existen por lo menos 13 artículos con un mínimo de 13 citas (7). En la Tabla 1 se presentan los artículos con $>15$ citas. 
Tabla 1. Artículos con $>15$ citas citados publicados en Mem. Inst. Investig. Cienc. Salud, periodo 2015-2020

\begin{tabular}{|c|c|c|c|c|}
\hline Posición & Citas & Autor (es) & Título & Año \\
\hline 1 & 37 & Soria \& $\operatorname{Ramos}^{(8)}$ & $\begin{array}{l}\text { Uso de plantas medicinales en la } \\
\text { atención primaria de salud en } \\
\text { Paraguay: algunas consideraciones } \\
\text { para su uso seguro y eficaz }\end{array}$ & 2015 \\
\hline 2 & 32 & $\begin{array}{l}\text { Acosta Colmán, Ávila, } \\
\text { Acosta, Aquino, Centurión \& } \\
\text { Duarte }^{(9)}\end{array}$ & $\begin{array}{l}\text { Manifestaciones clínicas y } \\
\text { laboratoriales en el Lupus } \\
\text { Eritematoso Sistémico-LES }\end{array}$ & 2016 \\
\hline 3 & 26 & $\begin{array}{l}\text { Maidana, Lugo, Vera, } \\
\text { Acosta, Morínigo, Isasi, et } \\
\text { al. }{ }^{(10)}\end{array}$ & $\begin{array}{l}\text { Factores que determinan la falta de } \\
\text { adherencia de pacientes diabéticos a } \\
\text { la terapia medicamentosa }\end{array}$ & 2016 \\
\hline 4 & 25 & Fariña $^{(11)}$ & $\begin{array}{l}\text { Resistencia bacteriana: un problema } \\
\text { de salud pública mundial de difícil } \\
\text { solución }\end{array}$ & 2016 \\
\hline 5 & 23 & $\begin{array}{l}\text { Giménez Caballero, } \\
\text { Rodríguez, Ocampos \& }^{\text {Flores }^{(12)}}\end{array}$ & $\begin{array}{l}\text { Composición del gasto de bolsillo en } \\
\text { el sistema de salud del Paraguay }\end{array}$ & 2017 \\
\hline \multirow[t]{2}{*}{6} & 20 & $\begin{array}{l}\text { Arrom Suhurt, Samudio, } \\
\text { Ruoti \& Orúe }{ }^{(13)}\end{array}$ & $\begin{array}{l}\text { Síndrome depresivo en la } \\
\text { adolescencia asociado a género, } \\
\text { abuso sexual, violencia física y } \\
\text { psicológica }\end{array}$ & 2015 \\
\hline & 20 & $\begin{array}{l}\text { Echagüe, Sosa, Díaz, } \\
\text { Funes, Rivas, Granado, et } \\
\text { al. }{ }^{(14)}\end{array}$ & $\begin{array}{l}\text { Malnutrición en niños menores de } 5 \\
\text { años indígenas y no indígenas de } \\
\text { zonas rurales, Paraguay }\end{array}$ & 2016 \\
\hline \multirow{3}{*}{7} & 16 & $\begin{array}{l}\text { Martínez-Locio \& } \\
\text { Hermosilla }^{(15)}\end{array}$ & $\begin{array}{l}\text { Razones de abandono de lactancia } \\
\text { materna en madres con hijos } \\
\text { menores de } 2 \text { años }\end{array}$ & 2017 \\
\hline & 16 & $\begin{array}{l}\text { Almirón, Denis, Morales, } \\
\text { Brítez, Macchi, Maidana, et } \\
\text { al. }{ }^{(16)}\end{array}$ & $\begin{array}{l}\text { Condiciones de salud oral en ancianos } \\
\text { del club geriátrico "Abue-Club" en } \\
\text { Paraguay }\end{array}$ & 2016 \\
\hline & 16 & $\begin{array}{l}\text { Agüero de Zaputovich \& } \\
\text { Samudio }^{(17)}\end{array}$ & $\begin{array}{l}\text { Características clínicas y } \\
\text { epidemiológicas de pacientes que } \\
\text { consultan por acné }\end{array}$ & 2015 \\
\hline
\end{tabular}

Los indicadores cienciométricos, aplicados al análisis y valoración de una publicación periódica, permiten dimensionar las tendencias que sigue la revista. De igual modo, es actualmente sabido que los datos obtenidos y las conclusiones evidenciadas son de ayuda para el mejoramiento de los procesos de gestión de las revistas $^{(18)}$.

En el caso de la revista Mem. Inst. Investig. Cienc. Salud, los indicadores cienciométricos hallados servirían para la continua consolidación del proceso y toma de decisiones editoriales de la revista, tomando en cuenta que la misma se está convirtiendo en referente científico del Paraguay y de la región latinoamericana.

\section{REFERENCIAS BIBLIOGRÁFICAS}

1. Arencibia-Arrebola DF, BetancourtLópez V, González-Alfalla N, PuigFernández $Y$, Biart-La Rosa $O$, Fernández-Sanguinety DF, et al. Estudio bibliométrico de la producción científica de VacciMonitor (2000-2013). VacciMonitor. 2014; 23 (2): 41-48.

2. Benet Rodríguez $M$, Morejón Giraldoni A. Posicionamiento de las revistas científicas de la salud en Cuba según el índice H5 obtenido del Google Scholar Metrics. Medisur. 2016; 14(2):180-188.

3. Gallardo Sánchez $Y$, Gallardo Arzuaga RL, Fonseca Arias M, Pérez Atencio ME.
Scientometric characterization of Medwave's scientific production 20102014. Medwave. 2016; 16(8): e6538. 10.5867/medwave.2016.08.6538

4. Morales Fernández T, Martínez Ramos AT, Rivas Corrías B, Diago Gómez A, Clavero Fleites L, Martínez Bernal S. Producción científica de la revista EDUMECENTRO y su visibilidad a través de Google Académico. EDUMECENTRO. 2017; 9(4):162-179.

5. Ladouceur R. Publish or perish. Can Fam Physician. 2019; 65(2):86. 
6. Harzing AW. Publish or perish; 2020 [citado 22 Ene 2021]. Disponible en: https://harzing.com/resources/publishor-perish

7. Dinis-Oliveira RJ. The $\mathrm{H}$-index in Life and Health Sciences: Advantages, Drawbacks and Challenging Opportunities. Curr Drug Res Rev. 2019; $11 \quad$ (2): 82-84. $10.2174 / 258997751102191111141801$

8. Soria N, Ramos P. Uso de plantas medicinales en la Atención Primaria de Salud en Paraguay: algunas consideraciones para su uso seguro y eficaz. Mem. Inst. Investig. Cienc. Salud. 2015; 13(2): 08-17. 10.18004/Mem.iics/18129528/2015.013(02)08-017

9. Acosta Colmán I, Ávila G, Acosta ME, Aquino $A$, Centurión $O$, Duarte $M$. Manifestaciones clínicas y laboratoriales en el Lupus Eritematoso Sistémico. Mem. Inst. Investig. Cienc. Salud. 2016; 14 (1): 94-109. 10.18004/Mem.iics/18129528/2016.014(01)94-109

10. Maidana GM, Lugo G, Vera Z, Acosta P, Morínigo M, Isasi $D$, et al. Factores que determinan la falta de adherencia de pacientes diabéticos a la terapia medicamentosa. Mem. Inst. Investig. Cienc. Salud. 2016; 14 (1): 70-77. 10.18004/Mem.iics/18129528/2016.014(01)70-077

11. Fariña N. Resistencia bacteriana: un problema de salud pública mundial de difícil solución. Mem. Inst. Investig. Cienc. Salud. 2016; 14(1):04-05. 10.18004/Mem.iics/18129528/2016.014(01)04-005

12. Giménez Caballero $\mathrm{E}$, Rodríguez JC, Ocampos G, Flores L. Composición del gasto de bolsillo en el sistema de salud del Paraguay. Mem. Inst. Investig. Cienc. Salud. 2017; 15(3): 64-72. 10.18004/mem.iics/18129528/2017.015(03)64-072
13. Arrom Suhurt $\mathrm{CH}$, Samudio $\mathrm{M}$, Ruoti M, Orúe E. Síndrome depresivo en la adolescencia asociado a género, abuso sexual, violencia física $y$ psicológica. Mem. Inst. Investig. Cienc. Salud. 2015;13(3):39-44. 10.18004/Mem.iics/1812-

9528/2015.013(03)39-044

14. Echagüe G, Sosa L, Díaz V, Funes P, Rivas L, Granado D, et al. Malnutrición en niños menores de 5 años indígenas y no indígenas de zonas rurales, Paraguay. Mem. Inst. Investig. Cienc. Salud. 2016;14(2):25-34.

10.18004/Mem.iics/1812-

9528/2016.014(02)25-034

15. Martínez-Locio $L$, Hermosilla $M$. Razones de abandono de lactancia materna en madres con hijos menores de 2 años. Mem. Inst. Investig. Cienc. Salud. 2017; 15(2):73-78.

$10.18004 / \mathrm{mem} . i \mathrm{ics} / 1812-$

9528/2017.015(02)73-078

16. Almirón PA, Denis SE, Morales $A$, Brítez E, Macchi AA, Maidana JA, et al. Condiciones de salud oral en ancianos del club geriátrico "AbueClub" en Paraguay. Mem. Inst. Investig. Cienc. Salud. 2016; 14(1):32-39.

10.18004/Mem.iics/1812-

9528/2016.014(01)32-039

17. Agüero de Zaputovich $F$, Samudio $M$. Características clínicas y epidemiológicas de pacientes que consultan por acné. Mem. Inst. Investig. Cienc. Salud. 2015; 13(1): 7-16. 10.18004/Mem.iics/18129528/2015.013(01)07-016

18. Corrales-Reyes I, Fornaris-Cedeño Y, Reyes-Pérez J, Valdés-Gamboa L. Aproximación cienciométrica a la producción científica de Medisur. Medisur. 2017; 15(5):640-646. 